\title{
Preoperative serum ST2 level predicts acute kidney injury after adult cardiac surgery
}

\author{
Kevin W. Lobdell, MD, ${ }^{\mathrm{a}}$ Devin M. Parker, MS, ${ }^{\mathrm{b}, \mathrm{c}}$ Donald S. Likosky, PhD, ${ }^{\mathrm{d}, \mathrm{e}}$ Michael Rezaee, MD, ${ }^{\mathrm{f}}$ \\ Moritz Wyler von Ballmoos, MD, PhD, MPH, FACC, ${ }^{g}$ Shama S. Alam, PhD, ${ }^{\text {b,c }}$ Sherry Owens, PhD, \\ Heather Thiessen-Philbrook, BMath, MMath, ${ }^{\mathrm{h}}$ Todd MacKenzie, $\mathrm{PhD},{ }^{\mathrm{b}, \mathrm{c}}$ and \\ Jeremiah R. Brown, PhD, MS ${ }^{\mathrm{b}, \mathrm{c}, \mathrm{i}}$
}

\section{ABSTRACT}

Objective: The purpose of this study was to evaluate the relationship between preoperative levels of serum soluble ST2 (ST2) and acute kidney injury (AKI) after cardiac surgery. Previous research has shown that biomarkers facilitate the prediction of AKI and other complications after cardiac surgery.

Methods: Preoperative ST2 proteins were measured in 1498 patients undergoing isolated coronary artery bypass graft surgery at 8 hospitals participating in the Northern New England Biomarker Study from 2004 to 2007. AKI severity was defined using the Acute Kidney Injury Network (AKIN) definition. Preoperative ST2 levels were measured using multiplex assays. Ordered logistic regression was used to examine the relationship between ST2 levels and levels of AKI severity.

Results: Participants in this study showed a significant association between elevated preoperative ST2 levels and acute kidney risk. Before adjustment, the odds of patients developing AKIN stage 2 or 3, compared with AKIN stage 1, are 2.43 times higher $(95 \%$ confidence interval, $1.86-3.16 ; P<.001)$ for patients in the highest tercile of preoperative ST2. After adjustment, patients in the highest tercile of preoperative ST2 had significantly greater odds of developing AKIN stage 2 or 3 AKI (odds ratio, 1.99; 95\% confidence interval, 1.50-2.65; $P<.001)$ compared with patients with AKIN stage 1 .

Conclusions: Preoperative ST2 levels are associated with postoperative AKI risk and can be used to identify patients at higher risk of developing AKI after cardiac surgery. (J Thorac Cardiovasc Surg 2018;156:1114-23)

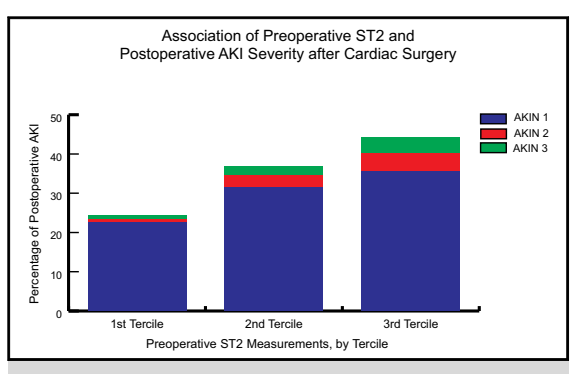

Preoperative ST2 levels and risk of acute kidney injury after cardiac surgery.

\section{Central Message}

The development of AKI after cardiac surgery is associated with increased morbidity and mortality. ST2 has been investigated in improving preoperative AKI risk forecasting.

\section{Perspective}

Acute kidney injury is a common complication of cardiac surgery and is associated with significant morbidity and mortality. A timely diagnosis would allow for earlier intervention and could improve patient outcomes. Our findings suggest that preoperative ST2 levels are associated with AKI and could potentially be used to identify patients at the highest risk of developing AKI in cardiac surgery.

See Editorial Commentary page 1124.
The development of acute kidney injury (AKI) after cardiac surgery is associated with increased morbidity and mortality. AKI is a common postoperative complication occurring in up to $40 \%$ of adult patients who undergo

From the ${ }^{\mathrm{a} C a r o l i n}$ as HealthCare System, Charlotte, $\mathrm{NC}$; ${ }^{\mathrm{b}}$ The Dartmouth Institute for Health Policy and Clinical Practice, Geisel School of Medicine, Lebanon, NH; ${ }^{c}$ Department of Medicine, Dartmouth-Hitchcock Medical Center, Lebanon, NH; ${ }^{\mathrm{d}}$ Institute for Healthcare Policy and Innovation, and ${ }^{\mathrm{e}}$ Section of Health Services Research and Quality, Department of Cardiac Surgery, University of Michigan, Ann Arbor, Mich; ' Section of Urology, Department of Surgery,

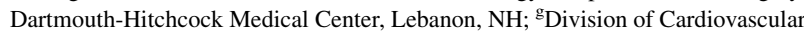
and Thoracic Surgery, Duke University Medical Center, Durham, NC; ${ }^{\text {h }}$ Program of Applied Translational Research, Section of Nephrology, Department of Medicine, Yale University School of Medicine, New Haven, Conn; and ${ }^{\mathrm{i}}$ Department of Community and Family Medicine, Geisel School of Medicine, Lebanon, NH. cardiac surgery. ${ }^{1-3}$ Identifying patients at increased risk of AKI is important to take preventative measures and counsel patients on potential outcomes after cardiac surgery. Previous research has examined risk factors

\footnotetext{
This research is supported by the National Heart Lung and Blood Institute R01HL119664 (PI: Brown). All authors are research staff or investigators on the grant.

Received for publication Sept 29, 2017; revisions received Feb 26, 2018; accepted for publication March 5, 2018; available ahead of print May 11, 2018.

Address for reprints: Jeremiah R. Brown, PhD, MS, HB 7505 Dartmouth-Hitchcock Medical Center, Lebanon, NH 03756 (E-mail: jbrown@ dartmouth.edu). $0022-5223 / \$ 36.00$

Copyright (C) 2018 by The American Association for Thoracic Surgery https://doi.org/10.1016/j.jtcvs.2018.03.149
} 


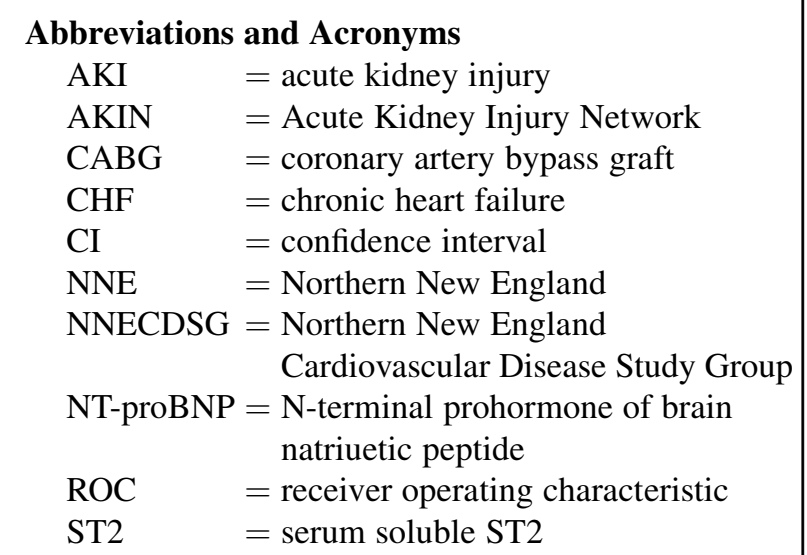

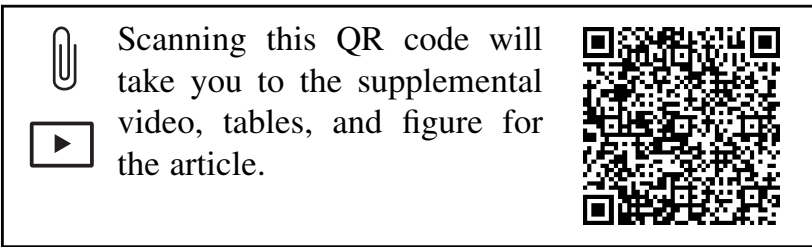

associated with the occurrence of postoperative AKI, largely focusing on preoperative factors, ${ }^{4-7}$ but also including perioperative risks such as transfusion requirements, bleeding, and low cardiac output. ${ }^{1,4-12}$ Preexisting renal dysfunction, hypertension, diabetes, and other cardiovascular comorbidities have traditionally identified patients at increased risk of AKI after surgery. ${ }^{1,4-12}$

A sensitive and specific marker of AKI risk could improve risk stratification, potentially identify patients who will benefit from greater care management before surgery, and alert clinicians to individuals who will need earlier interventions to prevent AKI. Although clinical and demographic variables have provided predictive value in identifying these patients, the additional use of specific serum biomarkers might further improve our ability to identify patients at risk of AKI.

Serum soluble ST2 (ST2) is a member of the interleukin1 receptor family of proteins, which play an important role in the regulation of immune and inflammatory response in the body. In the heart, ST2 has a biological role in the immunological process and is directly involved in a cardiac signaling pathway. Elevated levels of ST2 have been associated with myocardial infarction and volume overloaded hearts and might have a direct, adverse effect on kidney function. ${ }^{13-15}$ Soluble ST2 is an emerging biomarker that has been shown to predict adverse outcomes and death in individuals with established heart failure. ${ }^{16}$ ST2 has been investigated in risk stratification of mortality and offers promise in improving preoperative
AKI risk forecasting. ${ }^{17,18}$ The aim of this study was to determine the strength of the ST2 association with AKI after adjusting for traditional risk markers in adults who undergo cardiac surgery.

\section{METHODS \\ Cohort, Northern New England Biomarker Study}

This study expands on the experience of the Northern New England Cardiovascular Disease Study Group (NNECDSG), a regional collaborative consortium founded in 1987. The NNECDSG captures all coronary revascularizations and/or valve procedures in northern New England including 8 medical centers in Vermont, New Hampshire, and Maine. All hospitals in this consortium submit data on cases with validation of procedure numbers and mortality conducted every 2 years. The NNECDSG registry contains data on patient characteristics, procedural indications, clinical variables, and in-hospital outcomes. Data are periodically validated to ensure that all procedures and end points included in the registry have been accurately assessed. The Northern New England (NNE) Biomarker Study is an initiative designed to assess the role of biomarkers in cardiac surgery. ${ }^{19}$

Patient, procedural, and outcome data were collected from patients who underwent isolated coronary artery bypass graft (CABG) surgery at 8 hospitals participating in the NNE Biomarker Study from 2004 to 2007 ( $\mathrm{n}=1690$ ). For the present study, the sample included patients who underwent emergent, urgent, and nonurgent $\mathrm{CABG}$ surgeries. Those who underwent $\mathrm{CABG}$ incidental to heart valve repair or replacement, resection of a ventricular aneurysm, or other surgical procedure were not included. We excluded any patients who had preoperative renal failure $(\mathrm{n}=17)$. Only patients who had outcome data and whose biomarker levels collected were retained in the final analyses $(n=1498)$. The Committee for the Protection of Human Subjects at Dartmouth College (institutional review board) approved this study for the prospective cohort with patient consent as well as the linkage of readmission and mortality events.

\section{AKI}

The primary outcome of this study was the development of AKI after cardiac surgery. The change in the last serum creatinine level before sternotomy and highest postoperative serum creatinine level before discharge were used to classify the stage of AKI. AKI stages were defined by the Acute Kidney Injury Network (AKIN) definitions as follows: AKIN stage 1: 0.3 or $50 \%$ increase in serum creatinine level from baseline; AKIN stage 2: a twofold increase in serum creatinine; and AKIN stage 3: a threefold or 0.5 increase if the baseline serum creatinine level was at least $4.0(\mathrm{mg} / \mathrm{dL})$, or new dialysis-dependent renal failure. Because of the small proportion of patients in AKIN stage 2 and 3, we bundled stage 2 or 3 patient outcomes in this report. Urine output was not recorded in this prospective cohort.

\section{Soluble ST2}

Preoperative levels of soluble ST2 was the main exposure of interest for this study. Blood samples were preoperatively collected before incision at each participating site in a $10-\mathrm{mL}$ serum tube. Preoperative biomarker levels were measured using custom-made multiplex enzyme linked immunosorbent assays (Meso Scale Discovery, Rockville, Md). Blood was allowed to clot at room temperature for 20 minutes to separate out the red blood cells; the tubes were centrifuged at $3500 \mathrm{rpm}$ for 20 minutes, and the sera stored at the respective medical centers below $-80^{\circ} \mathrm{C}$ until transportation on dry ice to the Laboratory for Clinical and Biomedical Research in Colchester, Vermont where they were stored at $-80^{\circ} \mathrm{C}$ until measurement. Frozen serum was analyzed at a central laboratory, at the same time for biomarker measurement. Biomarkers were linked to the 
TABLE 1. Patient characteristics and postoperative AKI occurrence

\begin{tabular}{|c|c|c|c|c|}
\hline \multirow[b]{2}{*}{ Characteristic } & \multicolumn{3}{|c|}{ AKIN Stage } & \multirow[b]{2}{*}{$P$ value } \\
\hline & No AKIN $(n=972)$ & Stage $1(n=447)$ & Stage 2 or $3(n=79)$ & \\
\hline Age* & $64.0 \pm 10.0$ & $67.6 \pm 9.9$ & $71.0 \pm 9.5$ & .464 \\
\hline Female sex & $231(23.8 \%)$ & $100(22.4 \%)$ & $21(26.6 \%)$ & .680 \\
\hline BMI* & $29.2 \pm 5.2$ & $30.3 \pm 5.9$ & $30.5 \pm 7.1$ & .464 \\
\hline BSA, $\mathrm{m}^{2 *}$ & $2.0 \pm 0.2$ & $2.1 \pm 0.3$ & $2.0 \pm 0.3$ & .464 \\
\hline Smoker & $253(26.1 \%)$ & $72(16.1 \%)$ & $15(19.0 \%)$ & $<.001$ \\
\hline Atrial fibrillation & $51(5.2 \%)$ & $40(9.0 \%)$ & $9(11.4 \%)$ & .008 \\
\hline $\mathrm{CHF}$ & $82(8.4 \%)$ & $51(11.4 \%)$ & $20(25.3 \%)$ & $<.001$ \\
\hline Last preoperative serum creatinine* & $1.1 \pm 1.0$ & $1.1 \pm 0.4$ & $1.4 \pm 0.7$ & .464 \\
\hline Diabetes & $319(32.8 \%)$ & $189(42.3 \%)$ & $39(49.4 \%)$ & $<.001$ \\
\hline Ejection fraction $<40 \%$ & $82(8.9 \%)$ & $57(13.2 \%)$ & $14(18.9 \%)$ & .004 \\
\hline Hypertension & $780(80.2 \%)$ & $365(81.8 \%)$ & $63(80.8 \%)$ & .779 \\
\hline IABP preoperative & $31(3.2 \%)$ & $22(4.9 \%)$ & $8(10.1 \%)$ & .006 \\
\hline \multicolumn{5}{|l|}{ Previous MI } \\
\hline No & $580(59.7 \%)$ & $229(51.2 \%)$ & $33(41.8 \%)$ & .016 \\
\hline$<24$ h preoperatively & $15(1.5 \%)$ & $8(1.8 \%)$ & $2(2.5 \%)$ & \\
\hline$>24 \mathrm{~h}$ and $<7 \mathrm{~d}$ preoperatively & $172(17.7 \%)$ & $97(21.7 \%)$ & $18(22.8 \%)$ & \\
\hline$>7 \mathrm{~d}$ and $<365 \mathrm{~d}$ preoperatively & $82(8.4 \%)$ & $53(11.9 \%)$ & $13(16.5 \%)$ & \\
\hline$>365 \mathrm{~d}$ preoperatively & $123(12.7 \%)$ & $60(13.4 \%)$ & $13(16.5 \%)$ & \\
\hline Vascular disease & $238(24.5 \%)$ & $138(30.9 \%)$ & $33(41.8 \%)$ & $<.001$ \\
\hline Unstable angina & $533(55.3 \%)$ & $245(55.4 \%)$ & $47(59.5 \%)$ & .769 \\
\hline COPD & $121(12.4 \%)$ & $61(13.6 \%)$ & $14(17.7 \%)$ & .375 \\
\hline Left main, $\geq 50 \%$ stenosis & $324(33.3 \%)$ & $148(33.1 \%)$ & $36(45.6 \%)$ & .079 \\
\hline Previous CABG & $17(1.8 \%)$ & $10(2.3 \%)$ & $7(9.1 \%)$ & $<.001$ \\
\hline Previous PCI & $197(20.3 \%)$ & $75(16.8 \%)$ & $22(27.9 \%)$ & .051 \\
\hline \multicolumn{5}{|l|}{ Priority } \\
\hline Emergent & $15(1.5 \%)$ & $10(2.2 \%)$ & $4(5.1 \%)$ & .244 \\
\hline Urgent & $657(67.6 \%)$ & $303(67.8 \%)$ & $54(68.4 \%)$ & \\
\hline Nonurgent & $300(30.9 \%)$ & $134(30.0 \%)$ & $21(26.6 \%)$ & \\
\hline Received pRBC units & $283(29.2 \%)$ & $229(51.2 \%)$ & $60(76.0 \%)$ & $<.001$ \\
\hline \multicolumn{5}{|c|}{ Number of pRBC units given preoperatively } \\
\hline 0 & $955(98.5 \%)$ & $433(96.9 \%)$ & $79(100.0 \%)$ & .359 \\
\hline 1 & $4(0.4 \%)$ & $5(1.1 \%)$ & $0(0.0 \%)$ & \\
\hline 2 & $7(0.7 \%)$ & $7(1.6 \%)$ & $0(0.0 \%)$ & \\
\hline 3 or more & $4(0.4 \%)$ & $2(0.5 \%)$ & $0(0.0 \%)$ & \\
\hline
\end{tabular}

$A K I N$, Acute Kidney Injury Network; $B M I$, body mass index; $B S A$, body surface area; $C H F$, congestive heart failure; $I A B P$, intraoperative balloon pump; $M I$, myocardial infarction; $C O P D$, chronic obstructive pulmonary disease; $C A B G$, coronary artery bypass graft; $P C I$, percutaneous coronary intervention; $p R B C$, packed red blood cell. $*$ Mean $\pm \mathrm{SD}$

NNECDSG cohort to conduct the preoperative risk model. Biomarkers were evaluated as continuous variables, log-transformation, and terciles.

\section{Statistical Analysis}

We evaluated the ST2 measurements to determine the association with the primary outcome (AKI) using univariate and ordered logistic regression. Postoperative outcomes were compared using the $\chi^{2}$ tests, and continuous data were compared using the analysis of variance test with the Bonferroni correction. The NNE clinical mortality model was used for risk adjustment. ${ }^{20}$ To evaluate the association of the biomarker with AKI outcomes, we divided the cohort into terciles on the basis of ST2 values, where the lowest tercile is the reference group. We included indicator variables for the middle and highest terciles. We used mean imputation replacement method for missing values of continuous variables in the NNE clinical model and assumed that missing values of indicator variables were 0 . All biomarker values below the assay's lower quantitative limit were assigned the lower limit of detection. The performance of the risk model was assessed by measuring the total area under the receiver operating characteristic curve (ROC; or c-statistic). Standard errors and $95 \%$ confidence intervals (CIs) were estimated for the c-statistic using a bootstrap method. Model discrimination analyses were performed on various 
TABLE 2. Patient and patient characteristics according to terciles of preoperative ST2

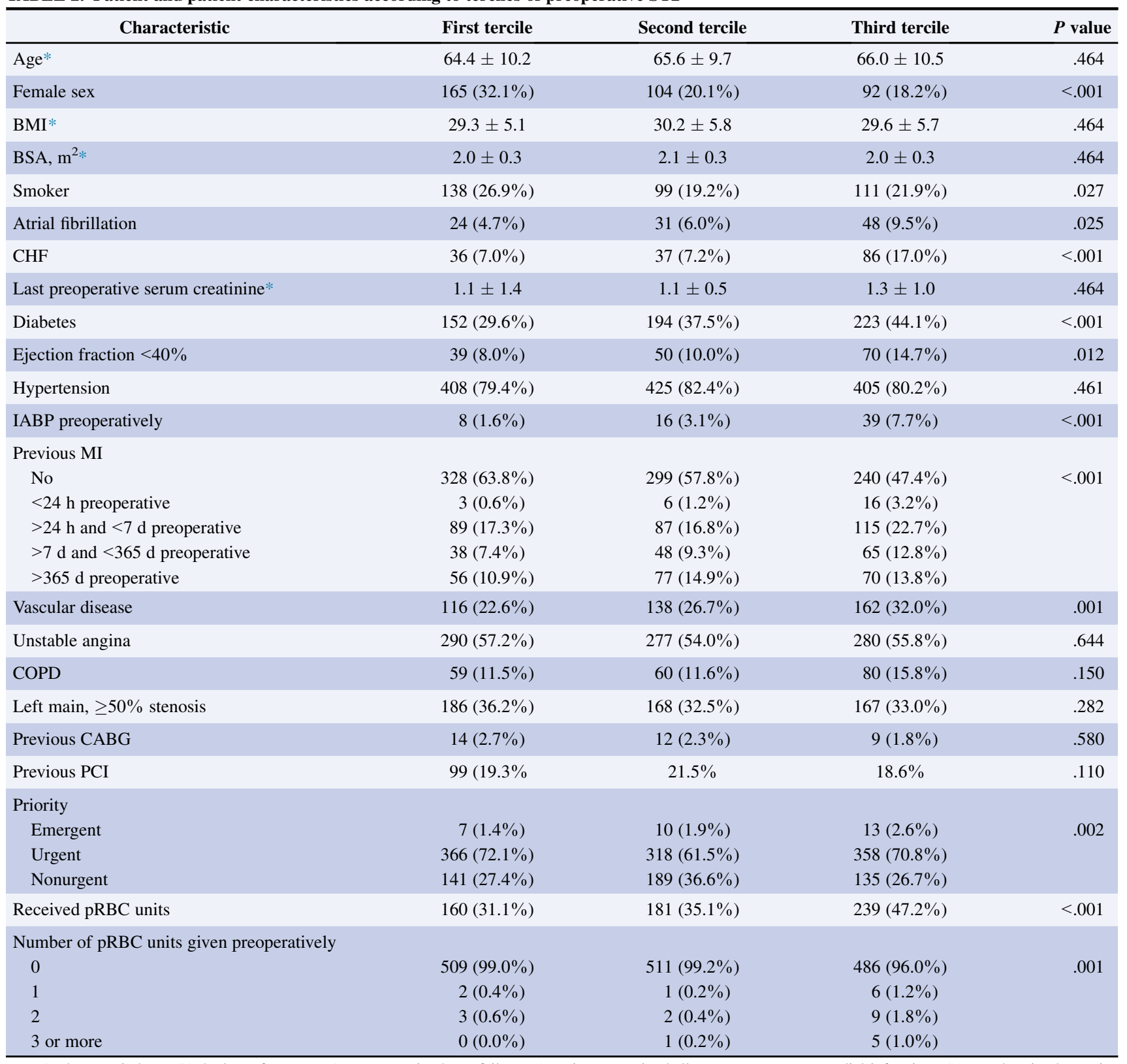

$B M I$, Body mass index; $B S A$, body surface area; $C H F$, congestive heart failure; IABP, intraoperative balloon pump; $M I$, myocardial infarction; $C O P D$, chronic obstructive pulmonary disease; $C A B G$, coronary artery bypass graft; $P C I$, percutaneous coronary intervention; $p R B C$, packed red blood cell. *Mean \pm SD.

biomarker cut points and serum creatinine values $>2$ and $>1.2 \mathrm{mg} / \mathrm{dL}$ to determine an optimal cut point. This process provided sensitivity, specificity, positive predictive values, and negative predictive values for the models.

\section{Secondary Analyses}

We sought to adjust for previously studied clinical factors associated with postoperative AKI. We created an additional multivariable model on the basis of the NNE mortality model but adjusted for the following additional covariates: chronic heart failure (CHF), diabetes, lower ejection fraction $(<40 \%)$, preoperative intra-aortic balloon pump, previous myocardial infarction, vascular disease, previous CABG surgery, and packed red blood cell units received in postoperative AKIN stage 2 to 3 occurrence group. We repeated our logistic and ordered logistic regression analyses using this augmented model.

We also compared the incremental value of ST2 with standard serum creatinine values, adjusting for the NNE preoperative clinical mortality model. We analyzed models first excluding serum creatinine level variables, then including preoperative serum creatinine levels $>2 \mathrm{mg} / \mathrm{dL}$ and $>1.2 \mathrm{mg} / \mathrm{dL}$, and finally including both measures of serum creatinine and ST2 levels. We used the test of equality of ROC areas to assess differences in model performance.

Finally, we created an alternative final multimarker model including preoperative biomarker $\mathrm{N}$-terminal prohormone of brain natriuetic peptide (NT-proBNP) values as well as preoperative ST2, in addition to the base NNE clinical mortality model, to assess the predictive power using a combination of cardiac biomarkers. We compared model performance 
using the test of equality of ROC areas. All analyses were conducted using Stata 13.1 (StataCorp, College Station, Tex).

\section{RESULTS}

Overall, 525 patients $(35.1 \%)$ developed AKI within AKIN-defined stage $1(29.8 \%)$ and stage 2 to $3(5.3 \%)$. Patient and procedural characteristics according to AKI outcome are summarized in Table 1. Patient and procedural characteristics according to ST2 terciles are summarized in Table 2. ST2 sample measurements ranged from 0.96 to $94.66 \mathrm{ng} / \mathrm{mL}$ with a median (quartile 1 to quartile 3 ) value of $3.82 \mathrm{ng} / \mathrm{mL}(2.87-5.17 \mathrm{ng} / \mathrm{mL})$. Patients with higher preoperative serum ST2 were more likely to be older and male, to be a smoker, to have congestive heart failure (CHF), diabetes, peripheral vascular disease, and were more likely to have had previous CABG surgery. There was a significant association between elevated preoperative ST2 levels and development of AKI $(P<.001)$. For patients in the lowest tercile of ST2, $22.5 \%$ experienced stage $1 \mathrm{AKI}$ compared with $35.6 \%$ in the highest biomarker tercile. Similarly, for patients in the highest tercile, $4.1 \%$ were classified as stage 3 AKI compared with $1.0 \%$ in the lowest tercile. There was a stepwise result of risk of postoperative AKI and elevated preoperative ST2 after cardiac surgery (Figure 1). The distribution of continuous ST2 and association with AKI is represented as a kernal density plot in Figure 2.

Table 3 shows the crude and adjusted results for the AKI risk model and preoperative ST2 biomarker terciles. Before adjustment, the odds of patients developing postoperative AKIN stage 2 or 3 , compared with AKIN stage 1, were 2.43 times higher $(95 \% \mathrm{CI}, 1.86-3.16 ; P<.001)$ for patients in the highest tercile of preoperative ST2. After adjustment, patients in the highest tercile had 1.99 greater odds of developing AKIN stage 2 or 3 AKI (95\% CI, 1.50-2.65; $P<.001$ ), compared with developing AKIN stage 1 .

Our preoperative model resulted in a ROC of $0.66(95 \%$ CI, 0.63-0.69), summarized in Table 4. In our augmented model, the addition of clinical factors CHF, diabetes, ejection fraction, preoperative intra-aortic balloon pump, previous myocardial infarction, vascular disease, previous

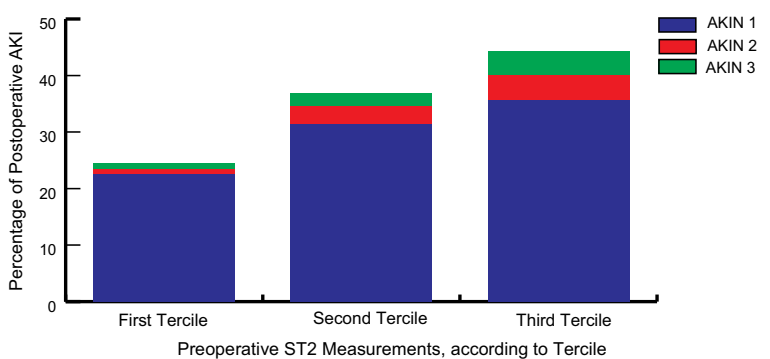

FIGURE 1. The association of elevated preoperative ST2 levels and patients who developed acute kidney injury (AKI) after cardiac surgery. $S T 2$, Serum soluble ST2; AKIN, Acute Kidney Injury Network.

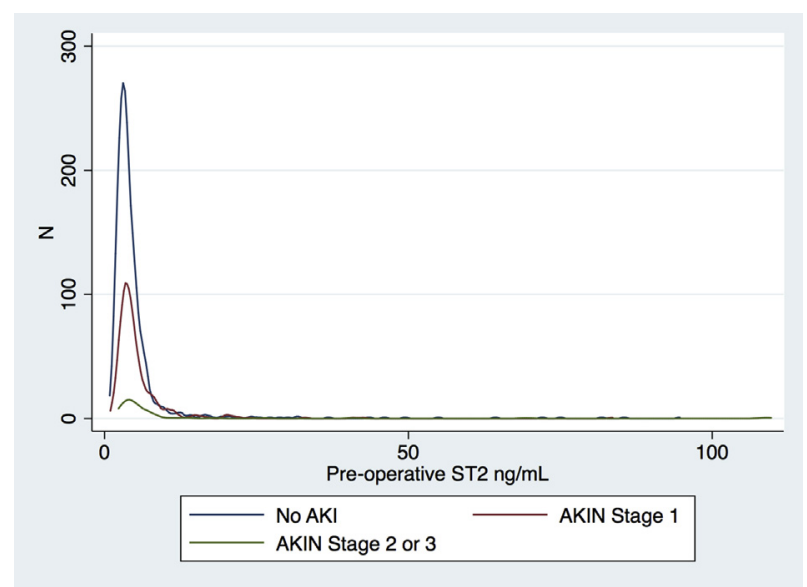

FIGURE 2. Kernel density plot of continuous serum soluble ST2 (ST2) measurements and acute kidney injury $(A K I)$. AKIN, Acute Kidney Injury Network.

CABG surgery, and packed red blood cell use to our preoperative model resulted in an improved ROC of 0.66 to 0.68 for preoperative ST2 terciles $(P=.013 ; 95 \% \mathrm{CI}$, $0.65-0.71)$. When we included postoperative ST2 values to the augmented model, our model improved significantly from ROC 0.66 to $0.72(P=.002 ; 95 \%$ CI, 0.68-0.75; Table 4).

We did not observe any significant difference in comparing the predictive ability of our preoperative model when we included preoperative serum creatinine $>2 \mathrm{mg} / \mathrm{dL}$ and serum creatinine $>1.2 \mathrm{mg} / \mathrm{dL}$. We also did not observe any difference in model prediction when we excluded serum creatinine levels. These models are listed in Tables 5 and 6. We compare the discriminatory power of preoperative serum creatinine and ST2 in predicting postoperative AKI in Tables 7 and 8. Postoperative characteristics and complications by terciles of ST2 and AKI status are described in Tables E1 and E2.

In our alternative final model, the addition of NT-proBNP resulted in an ROC improvement to $0.68(P<.001)$. We see

TABLE 3. Unadjusted and adjusted ordered logistic regression models with preoperative ST2 measurements and association with AKI severity

\begin{tabular}{llllll}
\hline & \multicolumn{2}{c}{ Unadjusted } & & \multicolumn{2}{c}{ Adjusted* } \\
\cline { 2 - 3 } \cline { 5 - 6 } ST2 & OR (95\% CI) & $\boldsymbol{P}$ value & & OR $(\mathbf{9 5} \%$ CI $)$ & $\boldsymbol{P}$ value \\
\hline Continuous & $1.02(1.00-1.04)$ & .015 & & $1.02(1.00-1.03)$ & .042 \\
Natural $\log$ & $1.76(1.45-2.14)$ & $<.001$ & & $1.57(1.29-1.91)$ & $<.001$ \\
Terciles & & & & \\
1 & REF & & REF & \\
2 & $1.76(1.34-2.30)$ & $<.001$ & $1.63(1.22-2.16)$ & .001 \\
3 & $2.43(1.86-3.16)$ & $<.001$ & $1.99(1.50-2.65)$ & $<.001$ \\
\hline
\end{tabular}

$S T 2$, Serum soluble ST2; $O R$, odds ratio; $C I$, confidence interval; $R E F$, reference. * Model adjusts for variables included in the NNE mortality model. 
TABLE 4. Augmented ordered regression model evaluating preoperative ST2 measurements and development of acute kidney injury after cardiac surgery

\begin{tabular}{|c|c|c|c|c|c|}
\hline \multirow[b]{2}{*}{ ST2 } & \multirow{2}{*}{$\frac{\text { Base NNE mortality model }}{\text { C-statistic }(95 \% \mathrm{CI})}$} & \multicolumn{2}{|c|}{ Augmented NNE model* } & \multicolumn{2}{|c|}{ Augmented NNE model with postoperative values } \\
\hline & & C-statistic (95\% CI) & $P$ value $\dagger$ & C-statistic $(95 \%$ CI $)$ & $P$ value $\nmid$ \\
\hline Continuous & $0.66(0.63-0.69)$ & $0.66(0.63-0.69)$ & .252 & $0.67(0.64-0.71)$ & .221 \\
\hline Natural log & $0.66(0.63-0.69)$ & $0.67(0.65-0.70)$ & .013 & $0.69(0.65-0.72)$ & .031 \\
\hline Terciles & $0.66(0.63-0.69)$ & $0.68(0.65-0.71)$ & .013 & $0.69(0.66-0.72)$ & .030 \\
\hline
\end{tabular}

ST2, Serum soluble ST2; NNE, Northern New England; $C I$, confidence interval. *Augmented NNE mortality model includes clinical factors: CHF, previous MI, preoperative IABP, and postoperative pRBC units received. †ROC comparison with NNE base model.

the inclusion of NT-proBNP significantly improves the discrimination of AKI preoperatively. Results from this model are listed in Table 6. The distribution of cases, according to hospital, are shown in Figure 3.

\section{DISCUSSION}

In this cohort study of adult patients who underwent cardiac surgery we showed a significant association of the protein soluble biomarker ST2 and postoperative AKI. The odds of patients developing postoperative AKIN stage 2 or 3, compared with AKIN stage 1, was nearly 2 times greater for patients in the highest tercile of preoperative ST2. To our knowledge, we are the first to show a significant association of elevated levels of ST2 as a prognostic indicator of AKI after cardiac surgery.

Recent research has shown that natriuretic peptides are particularly useful as diagnostic markers of heart failure and for the risk-stratification of patients. ${ }^{13}$ ST2 is independent of natriuretic peptide levels and thus might add additional predictive value that is not conflated with natriuretic peptide values. Soluble ST2 is a novel indicator of fibrosis that reflects cardiac dysfunction such as remodeling or postinjury scarring. ${ }^{14,15}$ ST2 is also a recognized biomarker that signals the presence and severity of adverse cardiac events including myocardial infarction, acute coronary syndrome, and worsening heart failure. Aldous et al reported that for patients with a primary outcome of death, heart failure, acute myocardial infarction, arrhythmia, or stroke, all had statistically higher median values of ST2 compared with those who did not have events. ${ }^{21}$

Transient increase of ST2 has been reported after myocardial infarction in mice subjected to coronary artery ligation. ${ }^{22}$ Increased levels of ST2 have been reported in the circulation of patients 1 day after acute myocardial infarction and correlated positively with creatine kinase. ${ }^{22}$ Additionally, studies have shown that high baseline levels of ST2 predicted congestive heart failure and mortality in patients with acute myocardial infarction at 30 days. To our knowledge, our study is the first to establish ST2 as an independent predictor of AKI among CABG patients in a large cohort of cardiac surgery patients.

TABLE 5. Assessing the incremental value of preoperative and postoperative ST2 and serum creatinine in predicting postoperative AKI

\begin{tabular}{|c|c|c|c|c|c|c|c|c|}
\hline \multirow[b]{2}{*}{ Model statistics } & \multirow{2}{*}{$\begin{array}{l}\text { C-statistic } \\
(95 \% \text { CI })\end{array}$} & \multicolumn{2}{|c|}{$\begin{array}{c}\text { Comparison with NNE } \\
\text { mortality model without } \\
\text { serum creatinine variables }\end{array}$} & \multicolumn{2}{|c|}{$\begin{array}{c}\text { Comparison with } \\
\text { NNE mortality model }\end{array}$} & \multicolumn{3}{|c|}{$\begin{array}{c}\text { Comparison with } \\
\text { NNE mortality model } \\
\text { with serum creatinine variables }\end{array}$} \\
\hline & & $P$ value & IDI $(95 \%$ CI $)$ & $P$ value & IDI $(95 \%$ CI) & $P$ value & IDI 95\% CI & $P$ value* \\
\hline Preoperative continuous & $0.66(0.63-0.69)$ & .066 & $0.01(0.00-0.02)$ & .180 & $0.00(0.00-0.01)$ & .152 & $0.00(0.00-0.01)$ & .269 \\
\hline Postoperative continuous & $0.70(0.67-0.73)$ & .000 & $0.06(0.04-0.08)$ & .001 & $0.05(0.03-0.06)$ & .000 & $0.05(0.03-0.06)$ & .269 \\
\hline $\begin{array}{l}\text { Pre- to postoperative } \\
\text { absolute difference }\end{array}$ & $0.70(0.66-0.73)$ & .000 & $0.06(0.04-0.07)$ & .001 & $0.05(0.03-0.06)$ & .000 & $0.05(0.03-0.06)$ & .269 \\
\hline Preoperative natural log & $0.67(0.65-0.70)$ & .004 & $0.02(0.01-0.03)$ & .011 & $0.01(0.01-0.02)$ & .000 & $0.01(0.01-0.02)$ & .269 \\
\hline Postoperative natural log & $0.70(0.67-0.73)$ & .000 & $0.06(0.04-0.07)$ & .001 & $0.05(0.03-0.06)$ & .000 & $0.05(0.03-0.06)$ & .269 \\
\hline $\begin{array}{l}\text { Pre- to postoperative } \\
\text { log difference }\end{array}$ & $0.68(0.64-0.71)$ & .025 & $0.03(0.02-0.04)$ & .089 & $0.02(0.01-0.03)$ & .000 & $0.02(0.01-0.03)$ & .269 \\
\hline Preoperative terciles & $0.68(0.65-0.71)$ & .005 & $0.02(0.02-0.03)$ & .014 & $0.02(0.01-0.02)$ & .000 & $0.01(0.01-0.02)$ & .269 \\
\hline Postoperative terciles & $0.69(0.66-0.73)$ & .001 & $0.05(0.03-0.06)$ & .004 & $0.04(0.02-0.05)$ & .000 & $0.03(0.02-0.05)$ & .269 \\
\hline Pre- to postoperative terciles & $0.69(0.66-0.72)$ & .002 & $0.04(0.03-0.06)$ & .009 & $0.03(0.02-0.04)$ & .000 & $0.03(0.02-0.04)$ & .269 \\
\hline $\begin{array}{l}\text { Pre- to postoperative log } \\
\text { difference terciles }\end{array}$ & $0.68(0.65-0.71)$ & .014 & $0.03(0.02-0.04)$ & .053 & $0.02(0.01-0.02)$ & .000 & $0.02(0.01-0.02)$ & .269 \\
\hline
\end{tabular}

CI, Confidence interval; NNE, Northern New England; IDI, integrated discrimination improvement. *ROC comparison against base model. 
TABLE 6. A multimarker model that includes preoperative ST2 and NT-proBNP biomarkers in improving prediction of postoperative AKI

\begin{tabular}{|c|c|c|c|c|}
\hline \multirow[b]{2}{*}{ Preoperative ST2 } & \multirow{2}{*}{$\frac{\text { Base model }}{\text { C-statistic }(95 \% \text { CI })}$} & \multicolumn{2}{|c|}{ Base model with preoperative ST2 and preoperative NT-proBNP } & \multirow[b]{2}{*}{$P$ value* } \\
\hline & & C-statistic (95\% CI) & $P$ value $\dagger$ & \\
\hline Continuous & $0.66(0.63-0.69)$ & $0.68(0.65-0.70)$ & .000 & .000 \\
\hline Natural log & $0.66(0.63-0.69)$ & $0.69(0.66-0.72)$ & .001 & .039 \\
\hline Terciles & $0.66(0.63-0.69)$ & $0.69(0.66-0.71)$ & .002 & .091 \\
\hline
\end{tabular}

$S T 2$, serum soluble ST2; NT-proBNP, N-terminal prohormone of brain natriuetic peptide; $C I$, confidence interval. ${ }^{*} P$ value (ROC comparison against base model with preoperative ST2 biomarker). $\dagger P$ value (ROC comparison against base model only).

Therefore, our study continues to extend the predictive ability of ST2 from exclusively cardiovascular outcomes to renal functioning outcomes. Future investigations should continue to explore the association between ST2 with cardiovascular as well as renal outcomes at the cellular level to determine the ways in which ST2 interacts with the kidney (Video 1).

\section{Comment}

Most renal and AKI risk models are static and do not currently consider biomarkers other than creatinine. ${ }^{23,24}$
Changes in serum creatinine commonly lag behind important clinical changes, making it a suboptimal marker. Although previously overlooked, small changes in serum creatinine and renal dysfunction-which exhibit a dose-dependent effect on mortality, morbidity, length of stay, readmissions, and costs associated with adult cardiac surgery-are increasingly scrutinized and studied. ${ }^{25-30}$ The importance of renal dysfunction as a postoperative complication is emphasized by the fact that acute renal failure has the highest rate of failure to rescue of the major complications associated with CABG surgery. ${ }^{31}$

TABLE 7. Comparing the discriminatory power of preoperative serum creatinine, various cut points of preoperative serum soluble ST2, and postoperative serum soluble ST2 in the prediction of postoperative AKI

\begin{tabular}{|c|c|c|c|c|}
\hline & PPV & NPV & Sensitivity & Specificity \\
\hline Preoperative continuous & 30.77 & 64.85 & 0.76 & 99.07 \\
\hline Postoperative continuous & 57.94 & 67.30 & 18.16 & 92.74 \\
\hline Pre- to postoperative absolute difference & 59.50 & 67.36 & 17.91 & 93.29 \\
\hline Preoperative natural log & 43.33 & 65.23 & 4.94 & 96.50 \\
\hline Postoperative natural log & 56.00 & 67.62 & 20.90 & 90.96 \\
\hline Pre- to postoperative log difference & 59.09 & 64.95 & 3.23 & 98.77 \\
\hline Preoperative above median & - & 64.89 & 0.00 & 100.00 \\
\hline Postoperative above median & - & 64.49 & 0.00 & 100.00 \\
\hline Above median of pre- to postoperative absolute difference & - & 64.49 & 0.00 & 100.00 \\
\hline Above median of pre- to postoperative log difference & - & 64.49 & 0.00 & 100.00 \\
\hline Preoperative terciles & - & 64.89 & 0.00 & 100.00 \\
\hline Postoperative terciles & - & 64.49 & 0.00 & 100.00 \\
\hline Terciles of pre- to postoperative absolute difference & - & 64.49 & 0.00 & 100.00 \\
\hline Terciles of pre- to postoperative log difference & - & 64.49 & 0.00 & 100.00 \\
\hline Preoperative quartiles & - & 64.89 & 0.00 & 100.00 \\
\hline Postoperative quartiles & 52.13 & 70.00 & 36.57 & 81.51 \\
\hline Quartiles of pre- to postoperative absolute difference & 51.44 & 69.67 & 35.57 & 81.51 \\
\hline Quartiles of pre- to postoperative log difference & - & 64.49 & 0.00 & 100.00 \\
\hline Preoperative quintiles & - & 64.89 & 0.00 & 100.00 \\
\hline Postoperative quintiles & 52.65 & 68.76 & 29.60 & 85.34 \\
\hline Quintiles of pre- to postoperative absolute difference & 52.23 & 68.61 & 29.10 & 85.34 \\
\hline Quintiles of pre- to postoperative log difference & - & 64.49 & 0.00 & 100.00 \\
\hline Preoperative serum creatinine $>2.0$ & 69.70 & 65.67 & 4.37 & 98.97 \\
\hline Preoperative serum creatinine $>1.2$ & - & 64.89 & 0.00 & 100.00 \\
\hline
\end{tabular}

$P P V$, Positive predictive value; $N P V$, negative predictive value. 
TABLE 8. Assessing the incremental value of preoperative ST2 and serum creatinine in predicting postoperative AKI

\begin{tabular}{|c|c|c|c|c|c|c|c|}
\hline & \multirow{2}{*}{$\frac{\text { Base model }}{\text { ROC }(95 \% \text { CI })}$} & \multicolumn{3}{|c|}{$\begin{array}{l}\text { Comparison with NNE mortality model } \\
\text { without any serum creatinine variables }\end{array}$} & \multicolumn{3}{|c|}{ Comparison with NNE mortality mode } \\
\hline & & $P$ value & IDI & IDI 95\% CI & $P$ value & IDI & IDI 95\% CI \\
\hline $\begin{array}{l}\text { NNE mortality model without } \\
\text { serum creatinine variables }\end{array}$ & $0.66(0.63-0.68)$ & & & & & & \\
\hline NNE mortality model & $0.66(0.63-0.69)$ & .213 & 0.01 & 0.00 to 0.01 & & & \\
\hline $\begin{array}{l}\text { NNE mortality model with } \\
\text { serum creatinine variables }\end{array}$ & $0.66(0.63-0.69)$ & .105 & 0.01 & 0.00 to 0.02 & .302 & 0.00 & 0.00 to 0.00 \\
\hline
\end{tabular}

Biomarkers offer considerable promise in AKI risk detection and assessment. Biomarkers might allow for earlier use of mitigation tactics (such as avoidance or delay of surgery, alteration in hemodynamic goals, and avoidance of potentially nephrotoxic medications). Personalized medicine might allow the physician to provide a better therapy for patients in terms of efficiency, safety, and treatment length to reduce the associated costs. Biomarker sampling should be used routinely to improve identification of patients at higher risk of AKI before cardiac surgery. Patient care management modifications can be made subsequent to patient stratification, including modifying perfusion practices and timing of surgery, can reduce the risk of AKI. Formal risk prediction of patients who undergo CABG surgery using a routinely assessed biomarker, along with routinely collected clinical information, has been shown to be cost-effective. ${ }^{32}$

Biomarkers for AKI risk assessment have been categorized as renal, cardiac, or general, and might be found in blood or urine. ${ }^{33}$ Cardiac biomarkers such as troponin and brain natriuretic peptide have been investigated and used to enhance preoperative risk assessment (including AKI). ${ }^{34,35}$ Similarly, the novel cardiac biomarker ST2 is a blood protein, which acts as a decoy receptor for interleukin-33 and is increased in myocardial infarction and volume-overloaded hearts. ${ }^{36}$ ST2 has been investigated in risk stratification of mortality independent of brain natriuretic peptide and offers promise in improving preoperative AKI risk forecasting. On the basis of our study, the combination of NT-proBNP and ST2 proves to be a helpful adjunct to existing risk models to identify individuals who are likely to develop postcardiac surgery AKI.

The primary strength of this study is the large sample size comprised of patients who underwent cardiac surgery at multiple hospitals across Maine, Vermont, and New Hampshire. Studies on preoperative biomarker levels and prediction of AKI has been previously conducted with small cohorts, in single-center settings, with a lack of defined, explicit outcomes. ${ }^{21}$ We leveraged the NNECDSG registry for this study, which is comprehensive in the patient and procedural data that it contains. The completeness and

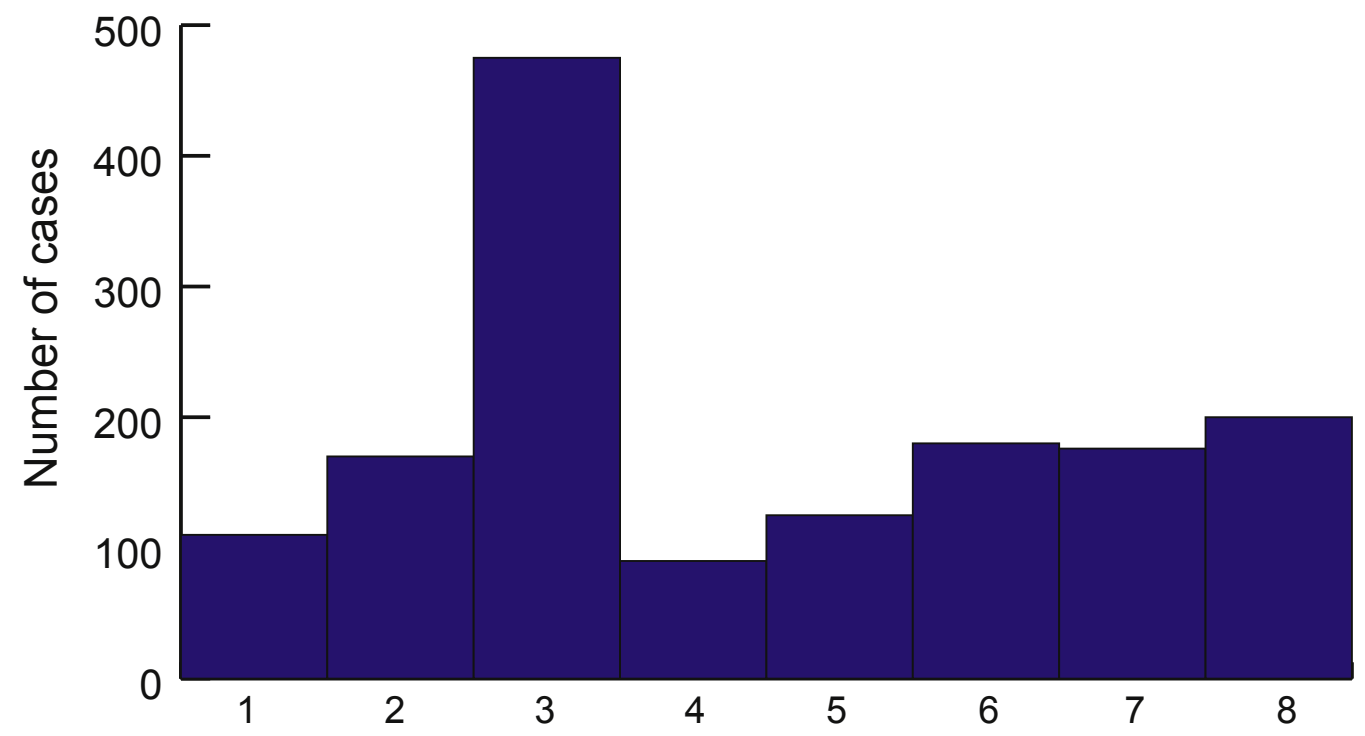

FIGURE 3. Distribution of number of cases according to hospital. 


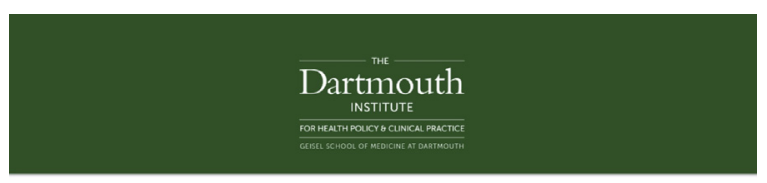

Preoperative Serum ST2 Levels Predicts Acute Kidney Injury After Adult Cardiac Surgery

\begin{abstract}
Kevin Lobdell, MD; Devin M. Parker, MS; Donald S. Likosky, Ph.D.; Michael
Rezaee, MD; Moritz Wyler von Ballmoos, MD, PhD, MPH, FACC; Shama Alam, PhD; Sherry Owens, PhD; Heather Thiessen-Philbrook, BMath, Alam, PhD; Sherry Owens, $\mathrm{PhD}$; Heather Thiessen-Philbrook,
MMath ; Todd Mackenzie, PhD; Jeremiah R. Brown, PhD, MS
\end{abstract}

VIDEO 1. The video provides a brief synopsis of the ST2 AKI findings, importance, and recommendations for surgical care teams how to act upon elevated ST2 levels known before cardiac surgery. Video available at: https://www.jtcvs.org/article/S0022-5223(18)30940-1/fulltext.

quality of the data help ensure that adequate adjustment was performed.

AKI is a frequent postoperative complication and occurs in up to $40 \%$ of adults after cardiac surgery, with $1 \%$ to $5 \%$ needing dialysis, in whom the mortality rate reaches $80 \%$. ${ }^{37}$

The development of AKI after cardiac surgery has been well studied in the past and is associated with poor outcomes and elevated mortality in patients. Although our data are from 2004 to 2007, AKI after cardiac surgery remains highly prevalent. ${ }^{38}$ Improved prediction of postoperative AKI should be of great interest to cardiac surgeons, caregivers, and patients, because it might allow for improved care management for patients.

Several limitations should be considered in the interpretation of our data. First, we lacked detailed information on some conditions known to affect the incidence of AKI including cardiopulmonary bypass times, hemodynamics, or the use of inotropic and vasoactive drugs in the perioperative period. Therefore, residual confounding of the demonstrated association of ST2 with AKI cannot be excluded. The association we showed after adjusting for many known risk markers of AKI and the remaining effect size suggest that these unavailable variables would be unlikely to explain the full effect we observed. Second, we also used creatinine-based definitions for AKI, which are relatively insensitive and nonspecific in the period directly after injury to the kidney. Finally, the multiple imputation method used to address missing data might influence the overall composition and performance of the model.

\section{CONCLUSIONS}

This study showed a significant relationship between protein-soluble biomarker ST2 and AKI severity in patients who undergo cardiac surgery. Our findings suggest that preoperative ST2 levels are associated with AKI and could potentially be used to identify patients at the highest risk of developing AKI in cardiac surgery.

\section{Conflict of Interest Statement}

Authors have nothing to disclose with regard to commercial support.

\section{References}

1. Parolari A, Pesce LL, Pacini D, Mazzanti V, Salis S, Sciacovelli C, et al. Risk factors for perioperative acute kidney injury after adult cardiac surgery: role of perioperative management. Ann Thorac Surg. 2012;93:584-91.

2. Vives M, Wijeysundera D, Marczin N, Monedero P, Rao V. Cardiac surgery-associated acute kidney injury. Interact Cardiovasc Thorac Surg. 2014;18:637-45.

3. Brown JR, Kramer RS, Coca SG, Parikh CR. Duration of acute kidney injury impacts long-term survival after cardiac surgery. Ann Thorac Surg. 2010;90: 1142-8.

4. Chertow GM, Lazarus JM, Christiansen CL, Cook EF, Hammermeister KE, Grover F, et al. Preoperative renal risk stratification. Circulation. 1997;95: 878-84.

5. Mehta RH, Grab JD, O'Brien SM, Bridges CR, Gammie JS, Haan CK, et al. Bedside tool for predicting the risk of postoperative dialysis in patients undergoing cardiac surgery. Circulation. 2006;114:2208-16.

6. Thakar CV, Arrigain S, Worley S, Yared JP, Paganini EP. A clinical score to predict acute renal failure after cardiac surgery. J Am Soc Nephrol. 2005;16: $162-8$.

7. Brown JR, Cochran RP, Leavitt BJ, Dacey LJ, Ross CS, MacKenzie TA, et al. Multivariable prediction of renal insufficiency developing after cardiac surgery. Circulation. 2007;116:I139-43.

8. Huen SC, Parikh CR. Predicting acute kidney injury after cardiac surgery: a systematic review. Ann Thorac Surg. 2012;93:337-47.

9. Palomba H, De Castro I, Neto A, Lage S, Yu L. Acute kidney injury prediction following elective cardiac surgery: AKICS Score. Kidney Int. 2007; 72:624-31.

10. Brown JR, Kramer RS, MacKenzie TA, Coca SG, Sint K, Parikh CR. Determinants of acute kidney injury duration after cardiac surgery: an externally validated tool. Ann Thorac Surg. 2012;93:570-6.

11. Rubino A, Torrisi S, Milazzo I, Fattouch K, Busà R, Mariani C, et al. Designing a new scoring system (QualyP Score) correlating the management of cardiopulmonary bypass to postoperative outcomes. Perfusion. 2015;30:448-56.

12. Stafford-Smith M. Invited commentary. Ann Thorac Surg. 2012;93:591.

13. Díez J. Serum soluble ST2 as a biochemical marker of acute heart failure. J Am Coll Cardiol. 2008;52:1466.

14. Moore SA, Januzzi JL Jr. Found in translation soluble ST2 and heart disease. J Am Coll Cardiol. 2010;55:251-3.

15. Dieplinger B, Januzzi JL, Steinmair M, Gabriel C, Poelz W, Haltmayer M, et al. Analytical and clinical evaluation of a novel high-sensitivity assay for measurement of soluble ST2 in human plasma-The Presage ST2 assay. Clin Chim Acta. 2009;409:33-40.

16. Bansal N, Katz R, Seliger S, DeFilippi C, Sarnak MJ, Delaney JA, et al. Galectin-3 and soluble ST2 and kidney function decline in older adults: the cardiovascular health study (CHS). Am J Kidney Dis. 2016;67:994-6.

17. Weinberg EO, Shimpo M, Hurwitz S, Tominaga SI, Rouleau JL, Lee RT. Identification of serum soluble ST2 receptor as a novel heart failure biomarker. Circulation. 2003; 107:721-6.

18. Mehta RL, Kellum JA, Shah SV, Molitoris BA, Ronco C, Warnock DG, et al. Acute Kidney Injury Network: report of an initiative to improve outcomes in acute kidney injury. Crit Care. 2007;11:R31.

19. Silver SA, Long J, Zheng Y, Chertow GM. Cost of acute kidney injury in hospitalized patients. J Hosp Med. 2017;12:70-6.

20. O'Brien SM, Clarke DR, Jacobs JP, Jacobs ML, Lacour-Gayet FG, Pizarro C, et al. An empirically based tool for analyzing mortality associated with congenital heart surgery. J Thorac Cardiovasc Surg. 2009;138: 1139-53.

21. Aldous SJ, Richards AM, Troughton R, Than M. ST2 has diagnostic and prognostic utility for all-cause mortality and heart failure in patients presenting to the emergency department with chest pain. J Card Fail. 2012;18: 304-10.

22. Weinberg EO, Shimpo M, De Keulenaer GW, MacGillivray C, Tominaga SI, Solomon SD, et al. Expression and regulation of ST2, an interleukin-1 receptor family member, in cardiomyocytes and myocardial infarction. Circulation. 2002;106:2961-6. 
23. Lobdell KW, Heniford BT, Sanchez JA. Managing the complex high-risk surgical patient. In: Sanchez J, Barach P, Johnson J, Jacobs J, eds. Surgical Patient Care. Cham, Switzerland: Springer; 2017:599-612.

24. Jiang W, Teng J, Xu J, Shen B, Wang Y, Fang Y, et al. Dynamic predictive scores for cardiac surgery-associated acute kidney injury. J Am Heart Assoc. 2016;5: e003754.

25. Lassnigg A, Schmidlin D, Mouhieddine M, Bachmann LM, Druml W, Bauer P, et al. Minimal changes of serum creatinine predict prognosis in patients after cardiothoracic surgery: a prospective cohort study. J Am Soc Nephrol. 2004;15:1597-605.

26. Howell NJ, Freemantle N, Bonser RS, Graham TR, Mascaro J, Rooney SJ, et al. Subtle changes in renal function are associated with differences in late survival following adult cardiac surgery. Eur J Cardiothorac Surg. 2012;41:e38-42.

27. LaPar DJ, Rich JB, Isbell JM, Brooks CH, Crosby IK, Yarboro LT, et al. Preoperative renal function predicts hospital costs and length of stay in coronary artery bypass grafting. Ann Thorac Surg. 2016;101:606-12.

28. Brown JR, Kramer RS, MacKenzie TA, Coca SG, Sint K, Parikh CR. Determinants of acute kidney injury duration after cardiac surgery: an externally validated tool. Ann Thorac Surg. 2012;93:570-6.

29. Brown JR, Hisey WM, Marshall EJ, Likosky DS, Nichols EL, Everett AD, et al. Acute kidney injury severity and long-term readmission and mortality after cardiac surgery. Ann Thorac Surg. 2016;102:1482-9.

30. Engoren M, Maile MD, Heung M, Jewell ES, Vahabzadeh C, Haft JW, et al. The association between urine output, creatinine elevation, and death. Ann Thorac Surg. 2017;103:1229-37.

31. Edwards FH, Ferraris VA, Kurlansky PA, Lobdell KW, He X, O’Brien SM, et al. Failure to rescue rates after coronary artery bypass grafting: an analysis from the Society of Thoracic Surgeons adult cardiac surgery database. Ann Thorac Surg. 2016;102:458-64.
32. Henriksson M, Palmer S, Chen R, Damant J, Fitzpatrick NK, Abrams K, et al Assessing the cost effectiveness of using prognostic biomarkers with decision models: case study in prioritising patients waiting for coronary artery surgery. BMJ. 2010;340:b5606.

33. Litton E, Ho KM. The use of pre-operative brain natriuretic peptides as a predictor of adverse outcomes after cardiac surgery: a systematic review and meta-analysis. Eur J Cardiothorac Surg. 2012;41:525-34.

34. Liu KD, Glidden DV, Eisner MD, Parsons PE, Ware LB, Wheeler A, et al Predictive and pathogenetic value of plasma biomarkers for acute kidney injury in patients with acute lung injury. Crit Care Med. 2007;35:2755-61.

35. McCullough PA, Olobatoke A, Vanhecke TE. Galectin-3: a novel blood test for the evaluation and management of patients with heart failure. Rev Cardiovasc Med. 2011:12:200-10.

36. Belley-Cote EP, Parikh CR, Shortt CR, Coca SG, Garg AX, Eikelboom JW et al. Association of cardiac biomarkers with acute kidney injury after cardiac surgery: a multicenter cohort study. J Thorac Cardiovasc Surg. 2016; 152:245-51.e4.

37. Parikh CR, Coca SG, Thiessen-Philbrook H, Shlipak MG, Koyner JL, Wang Z, et al. Postoperative biomarkers predict acute kidney injury and poor outcomes after adult cardiac surgery. J Am Soc Nephrol. 2011;22: 1748-57.

38. Karkouti K, Wijeysundera DN, Yau TM, Callum JL, Cheng DC, Crowther M, et al. Acute kidney injury after cardiac surgery: focus on modifiable risk factors. Circulation. 2009;119:495-502

Key Words: acute kidney injury, ST2, cardiac surgery, biomarkers

Readers who found these articles interesting may also like to read the following papers found in recent and future issues of our sister publications, Seminars in Thoracic and Cardiovascular Surgery and Operative Techniques in Thoracic and Cardiovascular Surgery!

\section{Adult: Perioperative Management}

ORIGINAL SUBMISSION: Early Outcomes with Rapid- Deployment Versus Stented Biological Valves: A Propensity-Match Analysis. Anthony Nguyen. Semin Thoracic Surg 2018:16-23.

Editorial Commentary: Rapid-Deployment Aortic Valve Replacement: Clear BenefitsWithout a Clear Target Patient Population. Craig M. Jarrett. Semin Thoracic Surg 2018:24-25.

ORIGINAL SUBMISSION: Randomized Trial of Carnitine for the Prevention of Perioperative Atrial Fibrillation. Farzaneh Dastan. Semin Thoracic Surg 2018:7-13.

Editorial Commentary: Preventing Postoperative Atrial Fibrillation: Is There One Best Option? Vincent R. Conti. Semin Thoracic Surg 2018:14-15. 


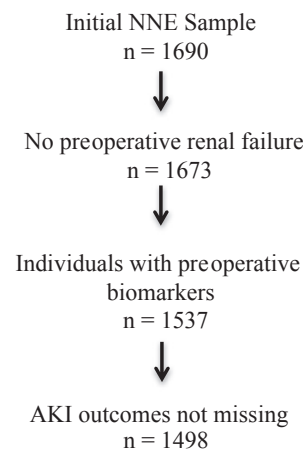

FIGURE E1. Patient flow diagram. NNE, Northern New England;

$A K I$, acute kidney injury.

TABLE E1. Postoperative complications according to terciles of preoperative ST2

\begin{tabular}{|c|c|c|c|c|}
\hline Complication & First tercile & Second tercile & Third tercile & $P$ value* \\
\hline Length of stay $\dagger$ & $7(6,10)$ & $7(6,10)$ & $8(6,13)$ & .000 \\
\hline Stroke intra- or postoperatively & $0.39 \%$ & $2.50 \%$ & $2.90 \%$ & .007 \\
\hline Transient ischemic attack postoperatively & $0.58 \%$ & $0.19 \%$ & $0.19 \%$ & .445 \\
\hline Return to OR for bleeding & $1.74 \%$ & $0.77 \%$ & $1.93 \%$ & .252 \\
\hline \multicolumn{5}{|c|}{ Mediastinitis/sternal dehisc requiring repeat surgery } \\
\hline No & $100.00 \%$ & $98.84 \%$ & $98.46 \%$ & .104 \\
\hline Yes, in-hospital & $0.00 \%$ & $0.96 \%$ & $1.16 \%$ & \\
\hline Yes, postdischarge & $0.00 \%$ & $0.19 \%$ & $0.39 \%$ & \\
\hline Postoperative leg wound infection & $0.19 \%$ & $1.16 \%$ & $1.35 \%$ & .108 \\
\hline Postoperative pneumonia & $0.97 \%$ & $2.50 \%$ & $3.47 \%$ & .026 \\
\hline New postoperative atrial fibrillation & $18.22 \%$ & $22.16 \%$ & $22.78 \%$ & .149 \\
\hline \multirow[t]{2}{*}{ Low output failure intra-/postoperative } & $4.13 \%$ & $6.67 \%$ & $8.46 \%$ & .018 \\
\hline & $6.98 \%$ & $7.32 \%$ & $17.76 \%$ & $<.001$ \\
\hline
\end{tabular}

OR, Odds ratio; dehisc, dehiscence. *Nonparametric test of trend was used for the continuous variable. $\dagger$ Median (25th percentile, 75 th percentile). 
TABLE E2. Postoperative characteristics according to AKI status

\begin{tabular}{|c|c|c|c|}
\hline Characteristic & No AKI & AKI & $P$ value \\
\hline Status at discharge & $0.31 \%$ & $4.18 \%$ & $<.001$ \\
\hline Length of stay $\dagger$ & $7(5,10)$ & $9(7,14)$ & .000 \\
\hline Stroke intra- or postoperatively & $1.23 \%$ & $2.85 \%$ & .025 \\
\hline Transient ischemic attack postoperatively & $0.41 \%$ & $0.19 \%$ & .478 \\
\hline Return to OR for bleeding & $1.03 \%$ & $2.28 \%$ & .054 \\
\hline \multicolumn{4}{|c|}{ Mediastinitis/Sternal dehisc requiring repeat surgery } \\
\hline No & $99.59 \%$ & $98.10 \%$ & .005 \\
\hline Yes, in-hospital & $0.21 \%$ & $1.71 \%$ & \\
\hline Yes, post-discharge & $0.21 \%$ & $0.19 \%$ & \\
\hline Postoperative leg wound infection & $0.51 \%$ & $1.71 \%$ & .022 \\
\hline Pneumonia postoperatively & $0.82 \%$ & $4.94 \%$ & $<.001$ \\
\hline New postoperative atrial fibrillation & $16.15 \%$ & $30.42 \%$ & $<.001$ \\
\hline Low output failure intra/postoperatively & $4.30 \%$ & $9.25 \%$ & $<.001$ \\
\hline
\end{tabular}

